\title{
Taxonomic and genetic assessment of captive White- Handed Gibbons (Hylobates lar) in Peninsular Malaysia with implications towards conservation translocation and reintroduction programmes
}

\author{
Millawati Gani ${ }^{*}$, Jeffrine J. Rovie-Ryan ${ }^{1,2^{*}}$, Frankie Thomas Sitam', \\ Noor Azleen Mohd Kulaimi', Chew Cheah Zheng, ${ }^{1,3}$, Aida Nur Atiqah ${ }^{1,3}$, \\ Nur Maisarah Abd Rahim ',4, Ahmad Azhar Mohammed'
}

I National Wildlife Forensic Laboratory, Ex-Situ Conservation Division, Department of Wildlife and National Parks, KM 10 Jalan Cheras, 56100 Kuala Lumpur, Malaysia 2 Faculty of Resource Science and Technology, Universiti Malaysia Sarawak, 94300 Kota Samarahan, Sarawak, Malaysia 3 Faculty of Science and Technology, Universiti Kebangsaan Malaysia, 43600 UKM, Bangi Selangor, Malaysia 4 Faculty of Science, Universiti Putra Malaysia, 43400 UPM Serdang, Selangor, Malaysia

Corresponding author: Jeffrine J. Rovie-Ryan (rjeffrine@unimas.my)

Academic editor: Matthew Tocheri | Received 20 August 2021 | Accepted 25 October 2021 | Published 8 December 2021

http://zoobank.org/585E11C5-4430-4E40-B0E8-E882EFD7C3D5

Citation: Gani M, Rovie-Ryan JJ, Sitam FT, Kulaimi NAM, Zheng CC, Atiqah AN, Rahim NMA, Mohammed AA (2021) Taxonomic and genetic assessment of captive White-Handed Gibbons (Hylobates lar) in Peninsular Malaysia with implications towards conservation translocation and reintroduction programmes. ZooKeys 1076: 25-41. https:// doi.org/10.3897/zookeys.1076.73262

\begin{abstract}
Conservation translocation and reintroduction for the purpose of repopulating and reinforcing extirpated or depleted populations has been recognised as an important conservation tool, particularly for gibbon conservation in the immediate future. Feasibility assessments involving multiple factors, including taxonomic and genetic assessment of rescued and captive gibbons, are imperative prior to translocation and reintroduction programmes. In this study, we attempt to determine the subspecies and origin of captive Hylobates lar, White-handed gibbons, from Peninsular Malaysia to assist in future translocation and reintroduction programmes. A total of 12 captive and rescued $H$. lar samples were analysed using the control region segment of mitochondrial DNA. Sequence analyses and phylogenetic trees constructed
\end{abstract}

* These authors have contributed equally to this work

Copyright Millawati Gani et al. This is an open access article distributed under the terms of the Creative Commons Attribution License (CC BY 4.0), which permits unrestricted use, distribution, and reproduction in any medium, provided the original author and source are credited. 
using neighbour-joining, maximum likelihood, Bayesian inference, and network methods congruently differentiate all 12 captive individuals used in this study from other $H$. lar subspecies suggesting that these individuals belong to the $H$. lar lar subspecies. In addition, two populations of $H$. l. lar were observed: (1) a southern population consisting of all 12 individuals from Peninsular Malaysia, and (2) a possible northern population represented by three individuals (from previous studies), which might have originated from the region between the Isthmus of Kra, Surat Thani-Krabi depression, and Kangar-Pattani. Our findings suggest that the complete control region segment can be used to determine the subspecies and origin of captive $H$. lar.

\section{Keywords}

Control region, mitochondrial DNA, northern and southern lar populations, phylogenetic relationships, subspecies determination

\section{Introduction}

Small apes (family Hylobatidae), also known as lesser apes, consist of 20 species of gibbons inhabiting Southeast Asia which are grouped into four extant genera: Hylobates, Hoolock, Nomascus, and Symphalangus. Within the genus Hylobates, nine species are currently recognised (Roos 2016; IUCN 2021); Hylobates abbotti Kloss, 1929, Hylobates agilis $\mathrm{F}$. Cuvier, 1821, Hylobates albibarbis Lyon, 1911, Hylobates funereus I. Geoffroy, 1850, Hylobates klossii (Miller, 1903), Hylobates lar (Linneaus, 1771), Hylobates moloch (Audebert, 1798), Hylobates muelleri Martin, 1841 and Hylobates pileatus (Gray, 1861); two species exist in Peninsular Malaysia namely H. agilis and H. lar. In Peninsular Malaysia, $H$. lar is distributed throughout except for a narrow region between Perak River (State of Perak) and Muda River (State of Kedah) that is inhabited by the congener, H. agilis (Brockelman \& Geissmann 2020). Both species are categorised as 'Endangered' by the IUCN Red List of Threatened Species (Brockelman and Geissmann 2020; Geissmann et al. 2020) and are 'Totally Protected' under the Wildlife Conservation Act 2010 enforced in Peninsular Malaysia. Illegal hunting for the food and pet trade as well as habitat loss due to anthropogenic activities (forest clearing for development and agriculture) have been identified as the major causes of the decline of more than $50 \%$ of $H$. lar populations in the wild across its range (Brockelman and Geissmann 2020).

Large numbers of captive gibbons kept in zoological parks (including zoos and rescue centers) are individuals rescued from the illegal pet trade, private collectors, and plantations as their habitats are cleared (Cheyne 2009; Nijman et al. 2009). Due to the threat faced by in-situ populations, conservation translocation and reintroduction of ex-situ populations (of rescued and captive individuals) for the purpose of repopulating and reinforcing extirpated or depleted populations has been recognised as an important conservation tool, particularly for gibbon conservation in the immediate future (Cheyne 2009; IUCN/SSC 2013; Campbell et al. 2015). However, before such conservation actions are taken, feasibility assessments involving multiple factors in- 
cluding taxonomic and genetic assessment of rescued and captive gibbons are imperative prior to any translocation and reintroduction programmes (Campbell et al. 2015).

To assess the taxonomic and genetic variation of gibbons, several molecular taxonomy studies have been conducted. However, most systematic studies on gibbons have focused mainly on interspecific variation (Chan et al. 2010, 2012, 2013; Israfil et al. 2011; Veeramah et al. 2015; Matsudaira and Ishida 2021) while only a few have investigated intraspecific variation (Andayani et al. 2001; Woodruff et al. 2005; Aifat and Md-Zain 2021). In particular, the taxonomic status of $H$. lar subspecies requires further examination as they are based on minor variations in body colour and fur polychromatism (Woodruff et al. 2005; Brockelman and Geissmann 2020). According to Roos et al. (2014), five subspecies of $H$. lar are currently recognised: $H$. l. lar (Linnaeus, 1771), H. l. carpenteri Groves, 1968, H. l. entelloides I. Geoffroy Saint-Hilaire, 1842, H. l. vestitus Miller, 1942, and H. l. yunnanensis Ma \& Y. Wang, 1986. In this study, we employ the control region (CR) gene segment, a more variable gene segment of the mitochondrial DNA (mtDNA) (Roos and Geissmann 2001; Woodruff et al. 2005; Whittaker et al. 2007; Rovie-Ryan et al. 2014), to assess the taxonomic and genetic variation of white-handed gibbons in captivity.

\section{Materials and methods}

\section{Samples and GenBank sequences}

A total of 12 unrelated $H$. lar samples were used in this study. The approximate locality of the individuals is described in Table 1 and shown in Figure 1. All rescued individuals were of known locality. The localities of the confiscated and surrendered individuals were recorded at the location of the confiscation (from dealers or private owners) or the location of the Department of Wildlife and National Parks (DWNP) offices where the animals were brought in. Currently, all of these individuals are at the National Wildlife Rescue Centre (NWRC) at Sungkai (State of Perak) and are currently under-going rehabilitation.

Blood samples were collected during routine health checks by authorised veterinarians and personnel of DWNP where all sampling protocols adhere to the rules and regulations of the relevant authorities in Peninsular Malaysia. In addition, available mtDNA CR sequences of Hylobates were downloaded from GenBank including the outgroup species, Symphalangus syndactylus (Siamang), as summarised in Suppl. material 1.

\section{DNA extraction, PCR amplification and DNA sequencing}

Total genomic DNA was extracted from the blood samples using the QIAamp DNeasy Blood and Tissue Kit following the manufacturer's protocol (Qiagen, Germany). We designed two new pairs of oligonucleotides to amplify the complete CR region of the mtDNA as shown in Table 2. 


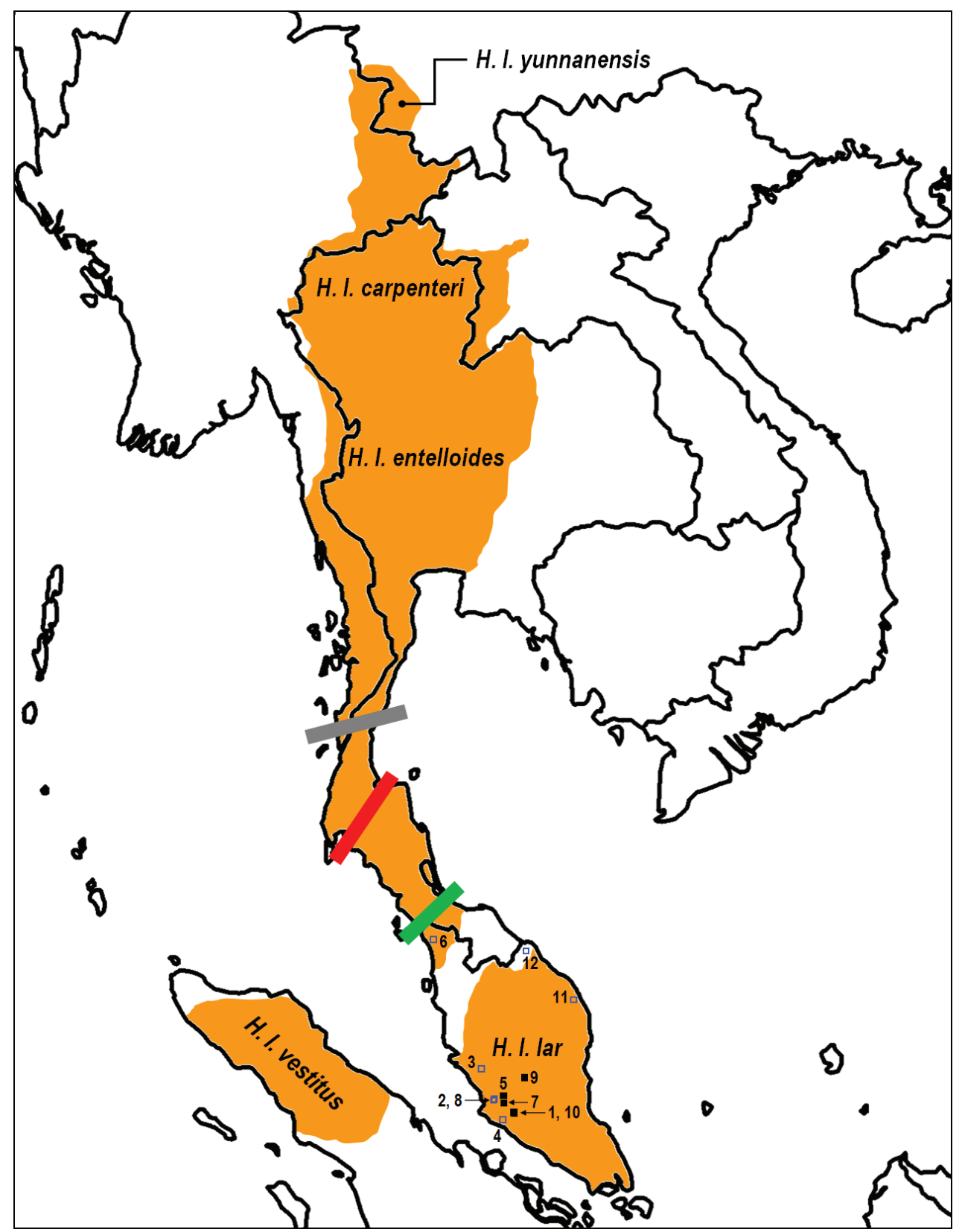

Figure I. Geographical distribution of Hylobates lar subspecies throughout South-East Asia (adapted from Thinh et al. 2010; Brockelman and Geissmann, 2020). Black squares represent individuals of known exact locations while blue squares indicated the approximate locations of the confiscated and surrendered individuals used in this study. Numbers on the map corresponds to the location in Table 1. The approximate location of the Isthmus of Kra, the Surat Thani-Krabi depression, and the Kangar-Pattani line are indicated by the grey, red, and green lines, respectively, marking the possible break among the Indochinese (carpenteri, entelloides, and yunnannesis) from the lar subspecies. 
Table I. Information of $H$. lar individuals used in this study. DWNP, Department of Wildlife and National Parks, Malaysia

\begin{tabular}{llcc}
\hline No. & \multicolumn{1}{c}{ Sample ID } & Sex & Description of locality (village, district, state) \\
\hline 1 & Betsy & F & Rescued from Kpg. Sg. Machang, Lenggeng, Negeri Sembilan* \\
2 & Lucy & F & Surrendered to DWNP Shah Alam, Selangor \\
3 & Chantiq & F & Confiscated from Sungai Dusun, Selangor \\
4 & Daly & M & Surrendered from Sepang, Selangor \\
5 & Keramat & F & Rescued from Taman Keramat, Kuala Lumpur* \\
6 & Abu & M & Surrendered to DWNP Alor Setar, Kedah \\
7 & Langat & F & Rescued from Hulu Langat, Selangor* \\
8 & Luca & M & Surrendered to DWNP Shah Alam, Selangor \\
9 & Daru & M & Rescued from Kpg. Asli Kuala Lompat, Krau, Pahang* \\
10 & Bella & F & Rescued from Kpg. Jeram Kedah, Lenggeng, N. Sembilan* \\
11. & PetPet & M & Surrendered from Kpg. Perpat, Ajil, Terengganu \\
12. & Lola & F & Confiscated from Pasir Mas, Kelantan \\
\hline
\end{tabular}

*Rescued individual were animals of known locality

Table 2. Two pairs of newly designed oligonucleotides used in this study to amplify the complete control region gene segment of the mitochondrial DNA.

\begin{tabular}{lrrcc}
\hline No. & Name & Oligonucleotide profile $\left(\mathbf{5}^{\prime}-\mathbf{3}^{\prime}\right)$ & Annealing temp. $\left({ }^{\circ} \mathbf{C}\right)$ & Product size $(\mathbf{b p})$ \\
\hline 1 & CR1-15391F* & ACT TAA CTT CAC CCT CAG CAC C & 50 & 550 \\
& CR1-15887R & ACC CCC AAG TGT TGT ARG CC & & 800
\end{tabular}

${ }^{*}$ Used for DNA sequencing

PCR amplifications were conducted in $20 \mu \mathrm{l}$ reactions using a T100 Thermal Cycler (Bio-Rad, USA) consisting of $1.0 \mu \mathrm{l}$ of DNA template $(-10$ to $20 \mathrm{ng}), 4 \mathrm{X}$ Green GoTaq Flexi Buffer (Promega, USA), $0.875 \mathrm{mM}^{\text {of }} \mathrm{MgCl}_{2}, 0.1 \mathrm{mM}$ of each dNTPs, $0.1 \mathrm{mM}$ of each primer, 1 unit of Taq polymerase, and added with $\mathrm{ddH}_{2} \mathrm{O}$ to make up a total of $20 \mu \mathrm{l}$ reaction mixtures. All amplifications were performed for 40 cycles each using the following profile: denaturation at $95^{\circ} \mathrm{C}$ for $30 \mathrm{~s}$, annealing at $50{ }^{\circ} \mathrm{C}$ for $30 \mathrm{~s}$, and extension at $72{ }^{\circ} \mathrm{C}$ for $45 \mathrm{~s}$, followed by a final extension step at $72{ }^{\circ} \mathrm{C}$ for 1 min. Successful PCR products were sent for sequencing on an ABI PRISM377 DNA Sequencer to a local sequencing service provider (Apical Scientific Pte. Ltd. Malaysia).

\section{DNA sequence analysis}

DNA sequences obtained were checked for quality and aligned using the software GENEIOUS PRIME 2021.1.1 (Biomatters 2020) before being examined manually. BLAST analysis (Altschul et al. 1990) showed sequence similarities ranging from $97.2 \%$ to $98.2 \%$ (with E-values less than or equal to 0 ) to $H$. lar from GenBank (AF311723), providing initial confirmation to rule out the chances of amplifying the nuclear copies of mitochondrial DNA (Numts). Secondly, as suggested by Sorenson and Quinn (1998), we designed our oligonucleotides using the gibbon reference sequence available in GenBank to maximise the chances of amplifying the CR segment and avoiding Numts. Thirdly, according to Spinks and Shaffer (2007), the presence 
of multiple peaks in a sequenced chromatogram indicates the presence of Numts. We confirmed that the sequences obtained in this study showed clear single peaks indicating that our amplification has avoided amplifying Numts. All sequences were later registered with GenBank with the Accession Numbers MZ407482 - MZ407493.

In total, $101 \mathrm{CR}$ sequences were included for subsequent analyses with aligned sequence lengths of 527-bp. DNA characteristics including conserved sites (CS), variable sites (VS), and parsimony informative sites (PIS) were checked using MEGA X (Kumar et al. 2018). Using DNASP 5.10.01 (Librado and Rozas 2009), DNA polymorphism analyses consisting of number of haplotypes (NHap), haplotype diversity ( $H d$ ), and nucleotide diversity, $\pi$ (Nei 1987) were calculated. Genetic distances among the sequences were also calculated using the Kimura-2 parameter model (Kimura 1980) on MEGA X.

\section{Phylogenetic tree construction}

In MEGA X, phylogenetic trees were constructed using neighbour-joining (NJ; distance based method) and maximum likelihood (ML). For the ML analysis, the HKY85 substitution model with a discrete Gamma distribution $(+\mathrm{G})$ with 5 rate categories (Hasegawa et al. 1985) was determined to be the best substitution model to run the ML tree, as calculated in MEGA X. The robustness of the NJ and ML trees were assessed by bootstrapping (Felsenstein 1985) with 1000 replicates. Bayesian inference (BI) was constructed using the BEAST 2.5 package (Bouckaert et al. 2019) on two independent runs each with 10 million Markov chain Monte Carlo (MCMC) generations and sub-sampled every 1000 generations using the following settings: HKY85 substitution model with five gamma category counts, strict clock, and Yule model (Heled and Drummond 2012). The convergence of the parameters was assessed using TRACER 1.7 (Rambaut et al. 2018). The log and tree files from both runs were then combined using LOGCOMBINER before TREEANNOTATOR (both software available within the BEAST package) was then used to create a consensus tree from the combined tree files with a burn-in of $10 \%$ and a posterior probability limit of 0.5 . FIGTREE 1.4 .4 (Rambaut 2018) was used to visualise the BI tree. Finally, to investigate the reticulate relationship among $H$. lar haplotypes, a median-joining network (MJN) tree analysis (Bandelt et al. 1999) was performed using NETWORK 10.2 (Fluxus Technology Ltd.).

\section{Results}

DNA sequence characteristics, DNA polymorphism, and genetic distances

Table 3 summarised the DNA characteristics and polymorphisms of the Hylobates species. Sequence characteristics of $H$. $\operatorname{lar}(N=57)$ showed $88 \mathrm{VS}$ and 46 PIS. In total, 49 lar haplotypes were observed with $\pi$ of $2.10 \%$. Haplotype mapping revealed that the 12 individuals of $H$. l. lar from Peninsular Malaysia are unrelated with an $H d$ of 0.99 . 
Table 3. DNA characteristics and polymorphisms calculated for the Hylobates used in this study. $N=$ number of sequences; $\mathrm{CV}=$ conserved sites; $\mathrm{VS}=$ variable sites; $\mathrm{PIS}=$ parsimony informative sites; NHap= number of haplotypes; $H d=$ haplotype diversity; $\pi=$ nucleotide diversity.

\begin{tabular}{lccccccc}
\hline \multicolumn{1}{c}{ Species } & $\boldsymbol{N}$ & \multicolumn{3}{c}{ DNA characteristics } & \multicolumn{3}{c}{ DNA polymorphism } \\
& & CV & VS & PIS & Nhap & Hd & $\boldsymbol{\pi}(\%)$ \\
\hline H. abbotti & 2 & 464 & 24 & 0 & 2 & 1.00 & 4.92 \\
H. agilis & 8 & 412 & 83 & 41 & 8 & 1.00 & 6.31 \\
H. albibarbis & 3 & 460 & 31 & 0 & 3 & 1.00 & 4.24 \\
H. klossi & 8 & 460 & 29 & 14 & 8 & 1.00 & 2.07 \\
H. lar & 57 & 403 & 88 & 46 & 49 & 0.99 & 2.10 \\
H. moloch & 9 & 454 & 37 & 15 & 9 & 1.00 & 2.35 \\
H. muelleri & 5 & 443 & 49 & 20 & 5 & 1.00 & 4.59 \\
H. pileatus & 8 & 469 & 23 & 8 & 8 & 1.00 & 1.51 \\
Total & 100 & 273 & 227 & 176 & 89 & 1.00 & 7.52 \\
\hline
\end{tabular}

Table 4. Genetic distances (in percentage, \%) calculated among the species within the genus Hylobates using the Kimura-2 parameter model (Kimura 1980).

\begin{tabular}{llcccccccc}
\hline No. & \multicolumn{1}{c}{ Species } & $\mathbf{1}$ & $\mathbf{2}$ & $\mathbf{3}$ & $\mathbf{4}$ & $\mathbf{5}$ & $\mathbf{6}$ & $\mathbf{7}$ & $\mathbf{8}$ \\
\hline $\mathbf{1}$ & H. abbotti & & & & & & & & \\
$\mathbf{2}$ & H. agilis & 13.75 & & & & & & & \\
$\mathbf{3}$ & H. albibarbis & 14.06 & 7.23 & & & & & & \\
$\mathbf{4}$ & H. klossii & 13.08 & 10.92 & 12.77 & & & & & \\
$\mathbf{5}$ & H. lar & 11.16 & 12.96 & 13.43 & 12.66 & & & & \\
$\mathbf{6}$ & H. moloch & 10.32 & 11.13 & 12.76 & 9.41 & 10.46 & & & \\
$\mathbf{7}$ & H. muelleri & 8.48 & 12.96 & 14.51 & 13.95 & 11.64 & 11.05 & & \\
$\mathbf{8}$ & H. pileatus & 18.60 & 18.59 & 19.93 & 17.95 & 14.31 & 15.81 & 16.54 & \\
$\mathbf{9}$ & Outgroup* & 25.94 & 24.45 & 26.43 & 22.58 & 23.63 & 22.57 & 25.90 & 24.90 \\
\hline
\end{tabular}

*Symphalangus syndactylus

Interestingly, we observed two transversion mutations at nucleotide positions (np) 165 (thymine/cytosine to adenine) and 259 (thymine/cytosine to adenine) which differentiated all the 12 individuals used in this study from all other $H$. lar sequences (Suppl. material 2). In addition, a transition mutation at np 193 (adenine to guanine) differentiated all 12 individuals from Peninsular Malaysia, as well as three sequences from GenBank (AF311723, LC548024, and LC548028), from other sequences of $H$. lar. On the other hand, the subspecies vestitus (represented by a single sequence, LC548011) showed three transversion mutations (at np 264, 287, and 348) and 10 transition mutations (Suppl. material 2) which separated it from the other subspecies.

Pairwise genetic distances among the species of Hylobates are shown in Table 4. In summary, species within the genus Hylobates differ from each other from $7.2 \%$ (between $H$. albibarbis and $H$. agilis) to $19.93 \%$ (between $H$. albibarbis and $H$. pileatus). Hylobates lar differed from the other Hylobates species ranging from 10.46 - $14.31 \%$. Genetic distances calculated for all $H$. lar ranged from $0.0-7.4 \%$ while distances among the $12 \mathrm{H}$. lar sequences from Peninsular Malaysia ranged from $0.2-3.4 \%$ (Suppl. material 3). 


\section{Phylogenetic trees and network analysis}

The phylogenetic trees constructed using the NJ, ML (log likelihood= -4326.23 ), and $\mathrm{BI}$ produced similar topologies and thus was summarised using the $\mathrm{NJ}$ tree as shown in Figure 2. Each species formed its own monophyletic clade (with high bootstrap and posterior probability support) except for $H$. albibarbis, which clustered within the $H$. agilis clade. Hylobates pileatus was the basal species of the genus Hylobates although with low support (below 50\% support). Hylobates lar was separated from all the other species with low to moderate support. Hylobates abotti and H. muelleri clustered together to form the Bornean species group (except for $H$. albibarbis) while $H$. moloch, $H$. klossii and $H$. agilis formed the Indonesian species group.

Within $H$. lar, we observed three possible subspecies groupings: (1) the basal $H$. l. vestitus, (2) H. l. lar (consisting of all 12 captive individuals from Peninsular Malaysia as well as the three sequences from GenBank mentioned above), and (3) a possible Indochinese subspecies group (representing $H$. l. entelloides, $H$. l. carpenteri, and $H$. l. yunnanensis). The Indochinese subspecies group did not show any obvious groupings according to subspecies. The $H$. l. lar group further splits with strong support (bootstrap and posterior probability) into two subgroups, which we tentatively define as representing northern and southern populations. The presumed northern $H$. l. lar population consists of three sequences from GenBank (of unknown origins) while the southern population consists of all 12 captive individuals from Peninsular Malaysia.

Similarly, the MJN tree constructed using the $H$. lar haplotypes $(N=49)$ produced similar groupings as the phylogenetic trees (Fig. 3). Hylobates l. vestitus differs from the Indochinese subspecies haplotypes and $H$. l. lar haplotypes (northern and southern) by at least 23 and 26 mutational steps, respectively. The northern $H$. l. lar haplotypes differ from the southern $H$. l. lar haplotypes by at least 10 mutational steps.

\section{Discussion}

A total of 1030-bp of the complete CR of mtDNA was successfully obtained from all 12 samples used in this study using the newly designed pairs of oligonucleotides. The CR segment of mtDNA is the most variable region and has been recommended as the appropriate segment to be used to infer gibbon phylogeny (Roos and Geissmann 2001; Woodruff et al. 2005; Whittaker et al. 2007; Matsudaira and Ishida 2010; Aifat and Md-Zain 2021). However, due to the lack of complete CR sequences of Hylobates in GenBank, a total of 527-bp of aligned dataset were analysed from 100 sequences representing all species of Hylobates except $H$. funereus. Our initial analysis of the complete CR sequence of $H$. lar (aligned sequence length of 1110-bp) showed an additional 59 VS and 34 PIS which may provide more informative data for the taxonomic and genetic assessment of $H$. lar. Therefore, we recommend the continued use of the complete CR segment in future studies of gibbon phylogeny and taxonomy. 


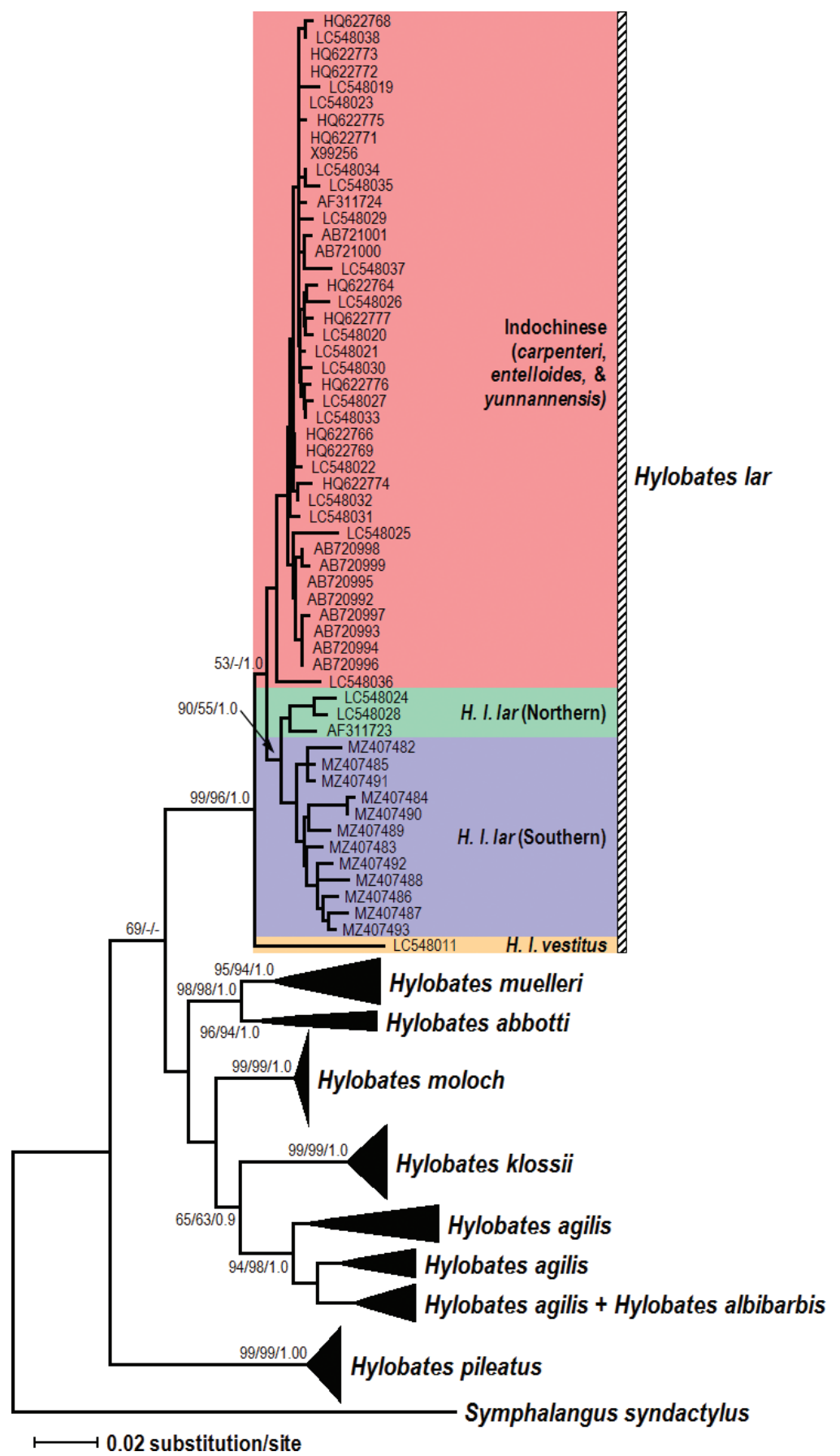

Figure 2. Phylogenetic relationships among the Hylobates species as represented by the NJ analysis. ML (Log Likelihood= -4326.23 ) and BI analysis produced similar topologies. Numbers above/below the branches represents bootstrap values for NJ, ML, and BI posterior probability, respectively. Only bootstrap values greater than $50 \%$ are shown. 


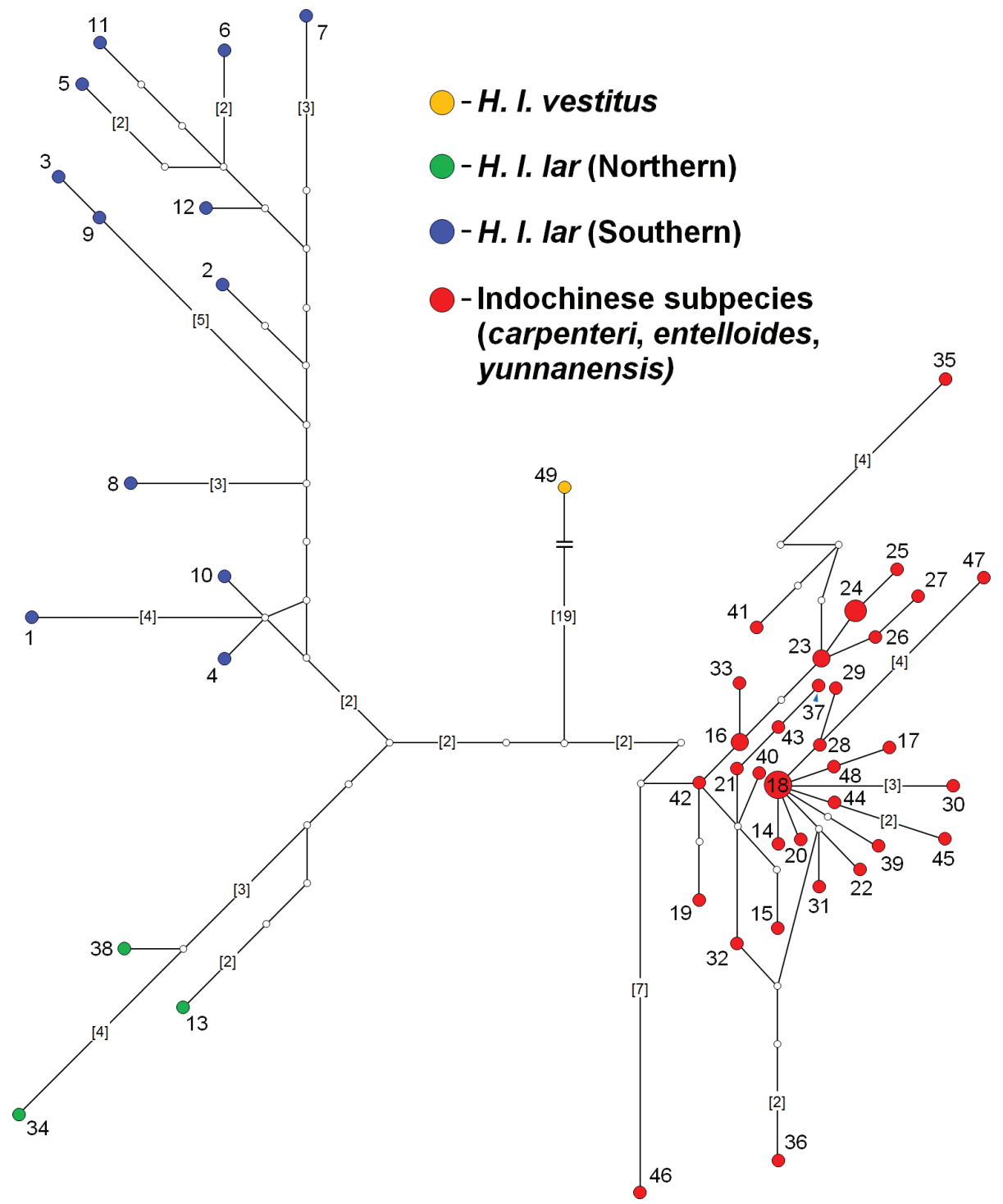

Figure 3. Median-joining network (MJN) constructed showing the relationships among the $H$. lar haplotypes. Each circle size is proportional to the number of individuals in each haplotype. The numbers next to the nodes correspond to the haplotype designation as listed in Supplementary Material, Table S1. The lines connecting the haplotypes represent single mutations unless indicated otherwise (numbers in parentheses). Hypothetical haplotypes (median vectors) are represented by white circles.

The phylogenetic relationships among Hylobates remain unresolved. Firstly, we observed H. pileatus as the basal species of Hylobates (although with low support), a result that is consistent with previous studies (Israfil et al. 2011; Chan et al. 2013; Matsudaira and Ishida 2021). Secondly, the relationships among the Sundaic species group (abbotti, agilis, albibarbis, klossii, moloch, and muelleri) remains conflated par- 
ticularly with regard to the basal species of this group (Thinh et al. 2010; Chan et al. 2013; Matsudaira and Ishida 2021). In this study, the Bornean species group (abbotti and muelleri) diverged first followed by the Indonesian species group (agilis, klossii, and moloch). The clustering of $H$. albibarbis within the $H$. agilis clade is expected because the subspecies albibarbis was initially classified as a subspecies of $H$. agilis (Thinh et al. 2010; Matsudaira and Ishida 2021).

The phylogenetic positioning of $H$. lar within the genus Hylobates concurs with findings from previous studies (Israfil et al. 2011; Chan et al. 2013; Matsudaira and Ishida 2021). Our phylogenetic and network analysis showed that $H$. l. vestitus from Sumatra diverged first (Thinh et al. 2010; Aifat and Md-Zain 2021; Matsudaira and Ishida 2021) before the proto- $H$. lar bifurcated to form the $H$. l. lar clade and the possible Indochinese subspecies clade (entelloides, carpenteri, and yunnanensis). However, the Indochinese subspecies clade did not show any obvious subspecies groupings. Note that most of the sequences of the Indochinese subspecies clade were obtained from zoo individuals of unknown origin and locality (Suppl. material 1) except for sequences by Matsudaira et al. (2013) (AB720992 - AB721001) which originated from individuals from Khao Yai National Park, Thailand representing the subspecies H. l. entelloides. Thus, we deduce these following scenarios to explain the condition: (1) Indochinese lar gibbons are represented by only one subspecies (entelloides) instead of three, (2) sequences of lar gibbons from GenBank of unknown locality were derived from only one subspecies, $H$. l. entelloides, and (3) the CR segment is not powerful enough to differentiate among the Indochinese subspecies. In view of the lack of information regarding the origin of the zoo animals as well as the lack of reference samples of known locality, these proposed scenarios must be regarded as hypothetical and preliminary. Future studies should therefore use individuals of known localities to correctly assign captive and rescued gibbons to their geographical provenance and origin.

Finally, our findings revealed that all 12 captive individuals used in this study belong to the H. l. lar subspecies. Aifat and Md-Zain (2021) used partial cytochrome $b$ gene segment of the mtDNA to successfully identify the subspecies of captive $H$. lar in Peninsular Malaysia but suggested that the CR segment be used in further studies on $H$. lar. The CR segment has been used in forensic investigations of various wildlife species to identify the subspecies and geographical origins of rescued or confiscated animals (Iyengar 2014). Interestingly, our results suggest the occurrence of two distinct populations of $H$. l. lar, as demarcated by two transversion mutations at np 165 and 259: (1) a southern population consisting of all 12 individuals from Peninsular Malaysia, and (2) a possible northern population of $H$. l. lar represented by three individuals from previous studies (AF311723, LC548024, and LC548028). These transversion mutations may be due to the prolonged isolation between the postulated southern and northern populations, which are separated by the presence of $H$. agilis in the narrow region between the Perak River and Muda River (Figure 1). Similar findings have been observed in other non-human primates, such as Macaca (Rovie-Ryan et al. 2021). Thus, these mutation sites should be used as genetic markers for future taxonomic and genetic assessments involving lar gibbons. The southern $H$. l. lar population likely 
consists of all populations south of the Kangar-Pattani line (Fig. 1) and including the entirety of Peninsular Malaysia. In contrast, the northern population may exist in regions between the Isthmus of Kra and the Kangar-Pattani line. Several previous studies have demonstrated the role of the Isthmus of Kra, the Surat Thani-Krabi depression, and the Kangar-Pattani line as zoogeographical boundaries between Sundaland and Indochina (Baltzer et al. 2007; Woodruff 2010; Hughes et al. 2011; Rovie-Ryan et al. 2013; Abdul-Latiff et al. 2014).

Overall, our findings support the importance of conducting taxonomic and genetic assessments prior to any gibbon translocations and/or reintroductions. The distinguishable differences between the postulated northern and southern $H$. l. lar populations warrant their treatment as separate management units (MUs), a component within the Evolutionary Significant Unit (ESU) (Moritz 1994). Although treated as separate MUs, under the circumstance that the remnant populations of lar are showing signs of inbreeding depression or increased fragmentation, mixing (translocation) between MUs are permittable (Moritz 1999).

In summary, we conclude that using the CR segment of the mtDNA, we could taxonomically distinguish $H$. l. lar from the other $H$. lar subspecies, an important result for future translocation and reintroduction programs of rescued and captive gibbons in Peninsular Malaysia. Nevertheless, the use of nuclear DNA data for taxonomic and genetic assessments of captive and rescued gibbons should also be considered, especially for individuals of suspected hybrid origin. Further studies are currently on-going by DWNP (as the authority of wildlife conservation and management) to screen all captive lar gibbons in Peninsular Malaysia as well as to collect reference samples from the wild.

\section{Acknowledgements}

We wish to thank the Director General and Director of the Ex-situ Conservation Division of DWNP for the support and permission to conduct this study. Special thanks to the following personnel for their assistance during sampling: Dr David Magintan, Dr Zubaidah Kamarudin, Dr Siti Suzana Selamat, and the Primate Team of the NWRC of DWNP. The project was funded by the Government of Malaysia under the $12^{\text {th }}$ Malaysia Plan Project: Strengthening Wildlife Forensics, Ex-Situ Conservation and Biobanking Phase 2 (Project Code: P23071000810008) lead by JJRR. We also thank UNIMAS for the Publication Support Fee. MG and JJRR share the first authorship of the manuscript.

\section{References}

Abdul-Latiff MAB, Ruslin F, Faiq H, Hairul MS, Rovie-Ryan JJ, Abdul-Patah P, Yaakop S, Md-Zain BM (2014) Continental monophyly and molecular divergence of Peninsular Malaysia’s Macaca fascicularis fascicularis. BioMed Research International 2014: e897682. https://doi.org/10.1155/2014/897682 
Aifat NR, Md-Zain BM (2021) Genetic identification of White-handed Gibbons (Hylobates lar) in captivity. Journal of Sustainability Science and Management 16(4): 316-326. https://doi.org/10.46754/jssm.2021.06.023

Altschul SF, Gish W, Miller W, Myers EW, Lipman DJ (1990) Basic Local Alignment Search Tool. Journal of Molecular Biology 215: 403-410. https://doi.org/10.1016/S00222836(05)80360-2

Andayani N, Morales JC, Forstner MRJ, Supriatna J, Melnick DJ (2001) Genetic variability in mtDNA of the silvery gibbon: Implications for the conservation of a critically endangered species. Conservation Biology 15(3): 770-775. https://doi.org/10.1046/j.15231739.2001.015003770.x

Baltzer JL, Davies SJ, Noor NSM, Kassim AR, LaFrankie JV 2007) Geographical distributions in tropical trees: Can geographical range predict performance and habitat association in co-occurring tree species? Journal of Biogeography 34(11): 1916-1926. https://doi. org/10.1111/j.1365-2699.2007.01739.x

Bandelt HJ, Forster P, Röhl A (1999) Median-joining networks for inferring intraspecific phylogenies. Molecular Biology and Evolution 16(1): 37-48. https://doi.org/10.1093/oxfordjournals.molbev.a026036

Biomatters (2020) Geneious - bioinformatics software for sequence data analysis. https://www. geneious.com/

Bouckaert R, Vaughan TG, Barido-Sottani J, Duchêne S, Fourment M, Gavryushkina A, Heled J, Jones G, Kühnert D, De Maio N, Matschiner M, Mendes FK, Müller NF, Ogilvie HA, du Plessis L, Popinga A, Rambaut A, Rasmussen D, Siveroni I, Suchard MA, Wu CH, Xie D, Zhang C, Stadler T, Drummond AJ (2019) BEAST 2.5: An advanced software platform for Bayesian evolutionary analysis. PLoS Computational Biology, 15(4): e1006650. https://doi.org/10.1371/journal.pcbi.1006650

Brockelman W, Geissmann T (2020) Hylobates lar. The IUCN Red List of Threatened Species 2020: eT10548A17967253. https://dx.doi.org/10.2305/IUCN.UK.2020-2.RLTS. T10548A17967253.en

Campbell CO, Cheyne SM, Rawson BM (2015) Best practice guidelines for the rehabilitation and translocation of gibbons. International Union for Conservation of Nature, Gland, Switzerland, 64 pp. https://doi.org/10.2305/iucn.ch.2015.ssc-op.51.en

Chan YC, Roos C, Inoue-Murayama M, Inoue E, Shih CC, Pei KJC, Vigilant L (2010) Mitochondrial genome sequences effectively reveal the phylogeny of Hylobates gibbons. PLoS One 5(12): e14419. https://doi.org/10.1371/journal.pone.0014419

Chan YC, Roos C, Inoue-Murayama M, Inoue E, Shih CC, Pei KJC, Vigilant L (2013) Inferring the evolutionary histories of divergences in Hylobates and Nomascus gibbons through multilocus sequence data. BMC Evolutionary Biology 13: e82. https://doi. org/10.1186/1471-2148-13-82

Chan C, Roos C, Inoue-Murayama M, Inoue E, Shih CC, Vigilant L (2012) A comparative analysis of $\mathrm{Y}$ chromosome and mtDNA phylogenies of the Hylobates gibbons. BMC Evolutionary Biology 12: e150. https://doi.org/10.1186/1471-2148-12-150

Cheyne SM (2009) The role of reintroduction in gibbon conservation: Opportunities and Challenges. In Whittaker D, Lappan S (Eds) The Gibbons. Developments in Primatol- 
ogy: Progress and prospects. Springer, New York, 477-496. https://doi.org/10.1007/9780-387-88604-6_23

Felsenstein J (1985) Confidence limits on phylogenies: An approach using the bootstrap. Evolution 39: 783-791. https://doi.org/10.1111/j.1558-5646.1985.tb00420.x

Geissmann T, Nijman V, Boonratana R, Brockelman W, Roos C, Nowak MG (2020) Hylobates agilis. The IUCN Red List of Threatened Species 2020: eT10543A17967655. https:// dx.doi.org/10.2305/IUCN.UK.2020-2.RLTS.T10543A17967655.en

Hasegawa M, Kishino H, Yano T (1985) Dating of the human-ape splitting by a molecular clock of mitochondrial DNA. Journal of Molecular Evolution 22: 160-174. https://doi. org/10.1007/BF02101694

Heled J, Drummond AJ (2012) Calibrated tree priors for relaxed phylogenetics and divergence time estimation. Systematic Biology 61(1): 138-149. https://doi.org/10.1093/sysbio/syr087

Hughes AC, Satasook C, Bates PJ, Bumrungsri S, Jones G (2011) Explaining the causes of the zoogeographic transition around the Isthmus of Kra: using bats as a case study. Journal of Biogeography 38(12): 2362-2372. https://doi.org/10.1111/j.1365-2699.2011.02568.x

Israfil H, Zehr SM, Mootnick AR, Ruvolo M, Steiper ME (2011) Unresolved molecular phylogenies of gibbons and siamangs (Family: Hylobatidae) based on mitochondrial, Ylinked, and X-linked loci indicate a rapid Miocene radiation or sudden vicariance event. Molecular Phylogenetics and Evolution 58(3): 447-455. https://doi.org/10.1016/j. ympev.2010.11.005

IUCN (2021) Hylobatidae. The IUCN Red List of Threatened Species. Version 2021-1. https://www.iucnredlist.org

IUCN/SSC (2013). Guidelines for Reintroductions and Other Conservation Translocations. Version 1.0. IUCN Species Survival Commission, Gland, Switzerland, viiii + 57 pp. https:// www.iucn.org/content/guidelines-reintroductions-and-other-conservation-translocations

Iyengar A (2014) Forensic DNA analysis for animal protection and biodiversity conservation: A review. Journal for Nature Conservation 22(3): 195-205. https://doi.org/10.1016/j. jnc.2013.12.001

Kimura M (1980) A simple method for estimating evolutionary rate of base substitutions through comparative studies of nucleotide sequences. Journal Molecular Evolution 16: 111-120. https://doi.org/10.1007/BF01731581

Kumar S, Stecher G, Li M, Knyaz C, Tamura K (2018) MEGA X: Molecular evolutionary genetics analysis across computing platforms. Molecular Biology and Evolution 35: 15471549. https://doi.org/10.1093/molbev/msy096

Librado P, Rozas J (2009) DnaSP v5: A software for comprehensive analysis of DNA polymorphism data. Bioinformatics 25: 1451-1452. https://doi.org/10.1093/bioinformatics/btp187

Matsudaira K, Ishida T (2010) Phylogenetic relationships and divergence dates of the whole mitochondrial genome sequences among three gibbon genera. Molecular Phylogenetics and Evolution 55(2): 454-459. https://doi.org/10.1016/j.ympev.2010.01.032

Matsudaira K, Ishida T (2021) Divergence and introgression in small apes, the genus Hylobates, revealed by reduced representation sequencing. Heredity 1-11. https://doi.org/https://doi. org/10.1038/s41437-021-00452-7 
Matsudaira K, Reichard UH, Malaivijitnond S, Ishida T (2013) Molecular evidence for the introgression between Hylobates lar and H. pileatus in the wild. Primates 54: 33-37. https:// doi.org/10.1007/s10329-012-0323-5

Moritz C (1994) Defining “evolutionary significant units” for conservation. Tree 9: 373-375.

Moritz C (1999) Conservation units and translocations: strategies for conserving evolutionary processes. Hereditas 130(3):217-228. https://doi.org/10.1111/j.1601-5223.1999.00217.x

Nei M (1987) Molecular Evolutionary Genetics. Columbia University Press, New York, 514 pp. https://doi.org/10.7312/nei-92038

Nijman V, Martinez CY, Shepherd CR (2009) Saved from trade: Donated and confiscated gibbons in zoos and rescue centres in Indonesia. Endangered Species Research 9(2): 151-157. https://doi.org/10.3354/esr00218

Rambaut A (2018) FigTree: Tree figure drawing tool version 1.4.4. http://tree.bio.ed.ac.uk/ software/figtree.

Rambaut A, Drummond AJ, Xie D, Baele G, Suchard MA (2018) Posterior summarisation in Bayesian phylogenetics using Tracer 1.7. Systematic Biology 67(5): 901-904. https://doi. org/10.1093/sysbio/syy032

Roos C (2016) Phylogeny and classification of gibbons (Hylobatidae). In Reichard UH, Hirai H, Barelli C (Eds) Evolution of gibbons and siamang. Developments in Primatology: Progress and prospects. Springer, New York, 151-164. https://doi.org/10.1007/978-1-4939-5614-2_7

Roos C, Boonratana R, Supriatna J, Fellowes JR, Groves CP, Nash SD, Rylands AB, Mittermeier RA (2014) An updated taxonomy and conservation status review of Asian primates. Asian Primates Journal 4(1): 2-38. http://paper.sci.ui.ac.id/jspui/handle/2808.28/108

Roos C, Geissmann T (2001) Molecular phylogeny of the major Hylobatid divisions. Molecular Phylogenetics and Evolution 19(3): 486-494. https://doi.org/10.1006/mpev.2001.0939

Rovie-Ryan JJ, Abdullah MT, Sitam FT, Abidin ZZ, Tan SG (2013) Y-chromosomal gene flow of Macaca fascicularis (Cercopithecidae) between the insular and mainland peninsula of Penang state, Malaysia. Journal of Science and Technology in the Tropics 9: 113-126.

Rovie-Ryan JJ, Abdullah MT, Sitam FT, Tan SG, Zainuddin ZZ, Basir MM, Abidin ZZ, Keliang C, Denel A, Joeneh E, Ali FM (2014) Genetic diversity of Macaca fascicularis (Cercopithecidae) from Penang, Malaysia as inferred from mitochondrial control region segment. Journal of Indonesian Natural History 2(1): 14-25. http://jinh.fmipa.unand.ac.id/index. $\mathrm{php} /$ jinh/article/view/27

Rovie-Ryan JJ, Khan FAA, Abdullah MT (2021) Evolutionary pattern of Macaca fascicularis in Southeast Asia inferred using Y-chromosomal gene. BMC Ecology and Evolution 21(1): 1-12. https://doi.org/10.1186/s12862-021-01757-1

Sorenson MD, Quinn TW (1998) Numts: A Challenge for Avian Systematics and Population Biology. The Auk 115(1): 214-221. https://doi.org/10.2307/4089130

Spinks PQ, Shaffer HB (2007) Conservation phylogenetics of the Asian box turtles (Geoemydidae, Cuora): Mitochondrial introgression, numts, and inferences from multiple nuclear loci. Conservation Genetics 8: 641-657. https://doi.org/10.1007/s10592-006-9210-1

Thinh VN, Mootnick AR, Geissmann T, Li M, Ziegler T, Agil M, Moisson P, Nadler T, Walter L, Roos C (2010) Mitochondrial evidence for multiple radiations in the evolutionary 
history of small apes. BMC Evolutionary Biology 10: 74. https://doi.org/10.1186/14712148-10-74.

Veeramah KR, Woerner AE, Johnstone L, Gut I, Gut M, Marques-Bonet T, Carbone L, Wall JD, Hammer MF (2015) Examining phylogenetic relationships among gibbon genera using whole genome sequence data using an approximate Bayesian computation approach. Genetics 200(1): 295-308. https://doi.org/10.1534/genetics.115.174425

Whittaker DJ, Morales JC, Melnick DJ (2007) Resolution of the Hylobates phylogeny: Congruence of mitochondrial D-loop sequences with molecular, behavioral, and morphological data sets. Molecular Phylogenetics and Evolution 45(2): 620-628. https://doi. org/10.1016/j.ympev.2007.08.009

Woodruff DS (2010) Biogeography and conservation in Southeast Asia: How 2.7 million years of repeated environmental fluctuations affect today's patterns and the future of the remaining refugial-phase biodiversity. Biodiversity and Conservation 19(4): 919-941. https://doi. org/10.1007/s10531-010-9783-3

Woodruff DS, Monda K, Simmons RE (2005) Mitochondrial DNA sequence variation and subspecific taxonomy in the white-handed gibbon, Hylobates lar. Natural History Journal of Chulalongkorn University Supplement 1, 71-78.

\section{Supplementary material I}

\section{Table S1. Summary table of all used sequences used in this study}

Authors: Millawati Gani, Jeffrine J. Rovie-Ryan, Frankie Thomas Sitam, Noor Azleen Mohd Kulaimi, Chew Cheah Zheng, Aida Nur Atiqah, Nur Maisarah Abd Rahim, Ahmad Azhar Mohammed

Data type: specimens data

Copyright notice: This dataset is made available under the Open Database License (http://opendatacommons.org/licenses/odbl/1.0/). The Open Database License $(\mathrm{ODbL})$ is a license agreement intended to allow users to freely share, modify, and use this Dataset while maintaining this same freedom for others, provided that the original source and author(s) are credited.

Link: https://doi.org/10.3897/zookeys.1076.73262.suppl1 


\section{Supplementary material 2}

Table S2. Variable regions observed among the Hylobates lar sequences

Authors: Millawati Gani, Jeffrine J. Rovie-Ryan, Frankie Thomas Sitam, Noor Azleen Mohd Kulaimi, Chew Cheah Zheng, Aida Nur Atiqah, Nur Maisarah Abd Rahim, Ahmad Azhar Mohammed

Data type: variable sites

Explanation note: Blue coloured boxed indicated transversion mutations while green boxes indicated transition mutations.

Copyright notice: This dataset is made available under the Open Database License (http://opendatacommons.org/licenses/odbl/1.0/). The Open Database License $(\mathrm{ODbL})$ is a license agreement intended to allow users to freely share, modify, and use this Dataset while maintaining this same freedom for others, provided that the original source and author(s) are credited.

Link: https://doi.org/10.3897/zookeys.1076.73262.suppl2

\section{Supplementary material 3}

Table S3. Pairwise genetic distances among the $H$. lar sequences used in this study using Kimura-2 parameters (Kimura 1980)

Authors: Millawati Gani, Jeffrine J. Rovie-Ryan, Frankie Thomas Sitam, Noor Azleen Mohd Kulaimi, Chew Cheah Zheng, Aida Nur Atiqah, Nur Maisarah Abd Rahim, Ahmad Azhar Mohammed

Data type: genetic distance

Copyright notice: This dataset is made available under the Open Database License (http://opendatacommons.org/licenses/odbl/1.0/). The Open Database License $(\mathrm{ODbL})$ is a license agreement intended to allow users to freely share, modify, and use this Dataset while maintaining this same freedom for others, provided that the original source and author(s) are credited.

Link: https://doi.org/10.3897/zookeys.1076.73262.suppl3 